\title{
Effect of increasing doses of mannitol on mucus clearance in patients with bronchiectasis
}

\author{
E. Daviskas*, S.D. Anderson*, S. Eberl ${ }^{*}$ and I.H. Young*
}

ABSTRACT: Bronchiectasis is characterised by hypersecretion and impaired clearance of mucus. A 400-mg dose of inhaled mannitol improves mucus clearance however, the effect of other doses is unknown.

A total of 14 patients, aged $63.3 \pm 5.7 \mathrm{yrs}$, were studied on five visits. Mucus clearance at baseline and with mannitol (160, 320 and $480 \mathrm{mg}$ ) was measured using technetium-99m-sulphur colloid and imaging with a gamma camera over $\mathbf{4 5}$ min, followed by a further $\mathbf{3 0}$ min involving 100 voluntary coughs. A control study assessed the effect of cough provoked by mannitol during the intervention.

Whole right lung clearance over 45 min was $4.7 \pm 1.2$ and $10.6 \pm 2.6 \%$ on baseline and control days, respectively, and increased to $16.7 \pm 4.2,22.8 \pm 4.2$ and $31 \pm 4.7 \%$ with 160,320 and $480 \mathrm{mg}$ mannitol, respectively. Clearance over $45 \mathrm{~min}$ with $480 \mathrm{mg}$ mannitol was greater than clearance with 320 and $160 \mathrm{mg}$. Total clearance over $75 \mathrm{~min}$, after mannitol administration and voluntary coughs, was $36.1 \pm 5.5,40.9 \pm 5.6$ and $46.0 \pm 5.2 \%$ with 160,320 and 480 mg mannitol, respectively, all significantly different from baseline $(24.1 \pm 6.0 \%)$ and control $(13.1 \pm 3.0 \%)$. Total clearance over 75 min with $480 \mathrm{mg}$ mannitol was greater compared with $160 \mathrm{mg}$.

In conclusion, mucus clearance increases with increasing doses of mannitol and can be further increased by cough in patients with bronchiectasis.

KEYWORDS: Bronchiectasis, hyperosmolarity, mannitol, mucus clearance

$B$ ronchiectasis patients usually have increased and persistent mucus secretion along with impaired mucociliary transport, which results in mucus accumulation, cough and recurrent infections [1-5]. Most patients with bronchiectasis are troubled by the disease and have a poor quality of life $[6,7]$. Treatment of mucociliary dysfunction consists mainly of pharmacological and physical therapy, which aim to reduce secretion or to increase clearance of mucus [8-12]. An improvement in the clearance of mucus by ciliary and cough action can be achieved by increasing the airway hydration and by optimising the viscoelastic and surface properties of mucus. This has been the role of mucoactive agents, such as osmotic agents, including mannitol.

Previous studies [4, 5] have confirmed that inhalation of $400 \mathrm{mg}$ of mannitol increased clearance of mucus acutely and over $24 \mathrm{~h}$ in bronchiectasis patients. In addition, mannitol improved the health-related quality of life in patients with bronchiectasis when administered over 2 weeks $[13,14]$.
Although it is clear that $400 \mathrm{mg}$ of mannitol is effective in improving clearance of mucus, it is not known whether this effect is dose dependent. In order to test that clearance of mucus increases with increasing doses of mannitol and that significant clearance of mucus can be achieved with doses $<400 \mathrm{mg}$ of mannitol, the present study investigated the effect of increasing doses of mannitol alone, and in association with cough, on the clearance of mucus in bronchiectasis patients.

\section{MATERIALS AND METHODS}

\section{Subjects}

A total of 14 subjects with stable bronchiectasis took part in the study (table 1). Bronchiectasis was diagnosed with a high-resolution computed tomography (HRCT) scan. Based on the HRCT scan, all subjects except one had extensive bronchiectasis involving at least the lower lobes, bilaterally. In one subject only, the bronchiectatic changes were localised on the lower left lobe and were reported as mild. None of the subjects had a diagnosis of cystic fibrosis and all had long-standing symptoms of bronchiectasis. All subjects withheld their

\section{AFFILIATIONS}

Depts of *Respiratory and Sleep Medicine, and

${ }^{\#}$ Positron Emission Tomography and Nuclear Medicine, Royal Prince Alfred Hospital, Camperdown, Australia.

CORRESPONDENCE

E. Daviskas

Dept of Respiratory and Sleep

Medicine

11 West

Royal Prince Alfred Hospital

Missenden Road

Camperdown

NSW 2050

Australia

Fax: 61295158196

E-mail: daviskas@med.usyd.edu.au

Received:

September 092007

Accepted after revision:

November 102007

\section{SUPPORT STATEMENT}

The study was supported by a grant from the National Health and Medical Research Council of Australia.

\section{STATEMENT OF INTEREST}

Statements of interest for all authors and for the study itself can be found at www.erj.ersjournals.com/misc/ statements.shtml 
regular medication (table 1 ) for $\sim 20 \mathrm{~h}$ on each study day. All subjects were never-smokers and none were being treated with antibiotics for exacerbations at the time of the study.

The present study was approved by the Ethics Review Committee of Sydney South West Area Health Service (Australia; Protocol No. X05 0259) and was performed under the Clinical Trial Notification Scheme of the Therapeutic Goods Administration of Australia (CTN No. 2005/602). Written informed consent was obtained from all subjects.

\section{Design of the study}

\section{Screening: visit 1}

An airway challenge with mannitol was performed in potential subjects following an approved protocol [15] in order to identify airway hyperresponsiveness to dry powder mannitol. Subjects were eligible to proceed to subsequent visits if they had a decrease in FEV1 to $<15 \%$ of baseline FEV1 after the airway challenge with mannitol. Subjects' medical histories and medications were recorded.

\section{Mucus clearance studies: visits 2-6}

There were five study days: 1) day 1, baseline; 2) day 2, administration of $160 \mathrm{mg}$ of mannitol; 3) day 3, administration of $320 \mathrm{mg}$ of mannitol; 4) day 4, administration of $480 \mathrm{mg}$ of mannitol; and 5) day 5, control. Study days 1-4 were randomised.

The procedures on each study day were: 1) spirometry; 2) radioaerosol inhalation; 3) dynamic imaging over $15 \mathrm{~min}$ in order to assess initial deposition and clearance of the radioaerosol; 4) intervention, consisting of either breathing while at rest, mannitol doses of 160,320 or $480 \mathrm{mg}$ or cough control over $15 \mathrm{~min}$; 5) dynamic imaging over $30 \mathrm{~min}$ in order to assess post-intervention clearance with and without mannitol; 6) dynamic imaging over a further $30 \mathrm{~min}$ in order to assess the effect of cough on days 1-4 (during this interval, subjects were asked to voluntarily cough deeply 100 times, corresponding to about 4 coughs $\cdot \mathrm{min}^{-1}$ ); and 7) spirometry.

On the baseline study day, subjects rested in the sitting position during the intervention period. On the control day, subjects were asked during the intervention period to inhale through the device loaded with an empty capsule and to cough the maximum number of spontaneous coughs counted on the mannitol test days. For this reason, the control study was performed last. In addition, the control study acted as a nocough control for the last $30 \mathrm{~min}$; therefore, no voluntary coughing was requested during this interval.

\section{Dry powder mannitol}

Dry powder mannitol (Pharmaxis Ltd, Frenchs Forest, Australia) was inhaled from capsules using the low-resistance dry powder inhaler (RS 01; Plastiape, Osnago, Italy). Mannitol was delivered in doses of $160 \mathrm{mg}$ (four capsules of $40 \mathrm{mg}$ ), $320 \mathrm{mg}$ (eight capsules of $40 \mathrm{mg}$ ) and $480 \mathrm{mg}$ (12 capsules of $40 \mathrm{mg})$.

\section{Measurement of lung function}

Spirometry was measured using a SpiroScore ${ }^{\circledR}$ card (Bird Healthcare, Melbourne, Australia). All subjects were clinically stable and had reproducible spirometry values (table 1). Predicted values for adults were taken from QUANJER et al. [16].

\section{Measurement of mucus clearance}

Clearance of mucus was measured using a radioaerosol technique and dynamic imaging with a double-head gamma camera (Biad; Trionix, Twinsburg, OH, USA). The radioaerosol, ${ }^{99 m}$ Tc-sulphur colloid (CIS-US Inc.; Bedford, MA, USA) was generated by a jet nebuliser (mass median aerodynamic diameter of the particles of $6.3 \mu \mathrm{m}$, span 2; Medic-Aid, Peckham, UK) at $8 \mathrm{~L} \cdot \mathrm{min}^{-1}$. Subjects inhaled the radioaerosol with a controlled breathing pattern following a

TABLE 1 Subject details and baseline lung function values

\begin{tabular}{|c|c|c|c|c|c|c|c|c|}
\hline Subject & Sex & Age yrs & Height $\mathbf{c m}$ & $\begin{array}{l}\text { FEV }_{1} \% \\
\text { pred }\end{array}$ & FEV $1 /$ FVC \% & FEF25-75\% pred & $\begin{array}{l}\text { FEV }_{1} \% \text { decrease post- } \\
635 \text { mg mannitol }\end{array}$ & Regular medication \\
\hline 1 & $\mathrm{~F}$ & 69 & 160 & 87 & 61 & 52 & 13.3 & Ciclesonide, salbutamol \\
\hline 2 & $\mathrm{~F}$ & 66 & 159 & 89 & 70 & 80 & -3.9 & Flixotide, salbutamol \\
\hline 3 & M & 56 & 179 & 44 & 60 & 34 & 0.7 & Salbutamol \\
\hline 4 & $\mathrm{~F}$ & 60 & 159 & 96 & 73 & 94 & 6.0 & Flixotide \\
\hline 7 & $\mathrm{~F}$ & 53 & 159 & 75 & 70 & 69 & 13.0 & Nil \\
\hline 8 & $F$ & 66 & 163 & 82 & 75 & 94 & 8.9 & Nil \\
\hline 9 & $\mathrm{~F}$ & 65 & 163 & 81 & 74 & 95 & 5.0 & Terbutaline, doxycycline \\
\hline 10 & $\mathrm{~F}$ & 68 & 163 & 86 & 59 & 73 & 8.3 & Terbutaline \\
\hline 11 & $\mathrm{~F}$ & 68 & 157 & 73 & 65 & 49 & 4.0 & Flixotide, salbutamol \\
\hline 12 & $\mathrm{~F}$ & 66 & 153 & 78 & 64 & 43 & 8.0 & Ciclesonide, salmeterol \\
\hline
\end{tabular}

FEV1: forced expiratory volume in one second; \% pred: \% predicted; FVC: forced vital capacity; FEF25-75\%: mean forced expiratory flow between 25 and $75 \%$ of FVC F: female; M: male. 
target volume of $450 \mathrm{~mL}$ and a target inspiratory time on a computer screen aimed at maximising deposition in the conducting airways $[4,5,17]$. The breathing pattern aimed at a peak inspiratory flow rate of $\sim 40 \mathrm{~L} \cdot \mathrm{min}^{-1}$. Approximately $5 \mathrm{~min}$ after the radioaerosol inhalation, simultaneous anterior and posterior dynamic imaging were commenced with a 1-min frame rate and the patient in the supine position. The lung fields of the subjects were delineated from a transmission scan with a cobalt- 57 sheet source.

All images were decay corrected to the imaging start time. The anterior and posterior transmission and emission images were combined into geometric mean (GM) images [18]. The right lung was divided into central, intermediate and peripheral regions [19]. The initial lung radioaerosol distribution (i.e. penetration index) was characterised by the ratio of the counts per pixel in the peripheral to the counts per pixel in the central region of the GM emission image obtained 5 min after the radioaerosol inhalation.

A mono- or bi-exponential function was fitted to each curve obtained from the dynamic GM images, using a nonlinear least squares method (IDL 5.0, Research Systems Inc, Boulder, Co, USA). The total counts of the whole right lung and defined regions in the first emission GM image were taken as $100 \%$ retention. The counts of the whole right lung and defined regions in the dynamic emission GM images, measured before and after the intervention were expressed as a percentage of the initial counts. The percentage retention curves gave an overall estimate of the total clearance from start $(100 \%$ retained). Activity that had not been retained had cleared. Counts from the best fit of the percentage retention curves were used to calculate total percentage clearance over the specified intervals as follows:

(counts at start of interval-counts at end of interval)

$\times 100 /$ counts at start of interval

\section{Statistical analysis}

A one-factor ANOVA with repeated measures was performed on the calculated total percentage clearance at the same specified intervals on the five study days. Post-hoc analysis was performed using Fisher-protected least significant difference. A p-value $<0.05$ was considered to be statistically significant. Data are presented as mean \pm SEM and $95 \%$ confidence intervals (CIs) are reported where applicable.

\section{RESULTS}

\section{Whole right lung}

Baseline day mucus clearance was very poor, $5.2 \pm 1.4 \%$ over the first $60 \mathrm{~min}$ without any intervention, as shown in the percentage retention curves (fig. 1). Clearance of mucus increased with all doses of mannitol compared with clearance measured on the baseline and control days (fig. 1, table 2).

Clearance over the 45-min period from the start of intervention increased with increasing doses of mannitol in the majority of subjects (table 2, fig. 2). Clearance with $480 \mathrm{mg}$ was significantly greater than clearance with 160 and $320 \mathrm{mg}$ mannitol (table 2, fig. 2). When the mannitol dose was increased from $160 \mathrm{mg}$ to $320 \mathrm{mg}$, the absolute increase (95\% CI) in clearance over $45 \mathrm{~min}$ was $6.1 \%(1.1-11.1 \% ; \mathrm{p}=0.07)$ and when increased to $480 \mathrm{mg}$ it was $14.3 \%(7.6-21.1 \% ; \mathrm{p}<0.0001)$. When the mannitol dose was increased from $320 \mathrm{mg}$ to $480 \mathrm{mg}$, the increase in clearance was $8.2 \%(3.2-13.2 \%$; $p<0.02)$. More importantly, the increase in clearance over $45 \mathrm{~min}$ with each mannitol dose compared with control was $6.1 \%(0.5-11.7 \%$; $\mathrm{p}=0.07), 12.2 \%(5.7-18.7 \% ; \mathrm{p}<0.001)$ and $20.4 \%(12.4-28.4 \%$; $\mathrm{p}<0.0001$ ) for 160,320 and $480 \mathrm{mg}$, respectively.

Clearance of mucus was further enhanced in response to 100 requested voluntary coughs (mean \pm SE $108 \pm 2 \%$ ) over a period of $30 \mathrm{~min}$ commenced $30 \mathrm{~min}$ after intervention. The cough clearance, calculated over this $30-\mathrm{min}$ period, was not dose dependent and not different to the clearance on the baseline study day $(21.3 \pm 5.9,24.3 \pm 4.3,24.4 \pm 5.2$ and $23.0 \pm 3.8 \%$ on the baseline day and for 160,320 and $480 \mathrm{mg}$ mannitol, respectively; $\mathrm{p}>0.5$ ). However, total clearance over $75 \mathrm{~min}$, taken from the start of intervention and including the 30 min cough period, with 160, 320 and $480 \mathrm{mg}$ mannitol was greater compared with clearance on baseline and control days (table 2). Total clearance with $480 \mathrm{mg}$ mannitol was $10 \%$ greater than that with $160 \mathrm{mg}(\mathrm{p}<0.03)$.

\section{Regional mucus clearance}

Clearance increased with increasing doses of mannitol in the central and intermediate regions, but not in the peripheral region (fig. 1, table 3 ). In the central and intermediate regions, clearance with $480 \mathrm{mg}$ mannitol was greater than clearance with $160 \mathrm{mg}$ and $320 \mathrm{mg}$ mannitol. In contrast, the increase in clearance in the peripheral region was similar with all doses.

The baseline day clearance over $45 \mathrm{~min}$ from start of intervention was very poor (table 3). All doses of mannitol significantly increased clearance over this period compared with baseline in all regions (table 3 ). Clearance on the control day, involving coughing without mannitol during the intervention period, was not significantly increased during this 45 -min period in any region over the baseline day clearance. Clearance with all doses of mannitol was greater than clearance on the control day in all regions, with the exception of the lowest dose of mannitol used $(160 \mathrm{mg})$, which was similar to control in the central region over $45 \mathrm{~min}$ (table 4). Clearance started to increase during the intervention period while mannitol was inhaled, except in the peripheral region where it started to increase in the post-intervention period.

Clearance with all doses of mannitol was further increased in all regions after the 100 voluntary coughs over $30 \mathrm{~min}$. However, the cough clearance over the 30-min period was not dose dependent and not different, in any region, to the clearance on the baseline study day. In the central region, cough clearance was $28.2 \pm 6.8,31.1 \pm 5.9,32.7 \pm 6.4$ and $31.4 \pm 3.9 \%$ on the baseline day and with 160,320 and $480 \mathrm{mg}$ mannitol, respectively $(\mathrm{p}>0.4)$. Total clearance over the $75 \mathrm{~min}$, taken from the start of intervention, was significantly increased with all doses compared with baseline in all regions (table 3). Total clearance with $480 \mathrm{mg}$ was almost double compared with baseline and triple compared with control in all regions (fig. 1 and table 3).

The number of coughs provoked by mannitol inhalation and all spontaneous coughs are shown in figure 3 . There was no significant difference in the number of spontaneous coughs provoked by mannitol $(\mathrm{p}>0.06)$. In addition, there was no 


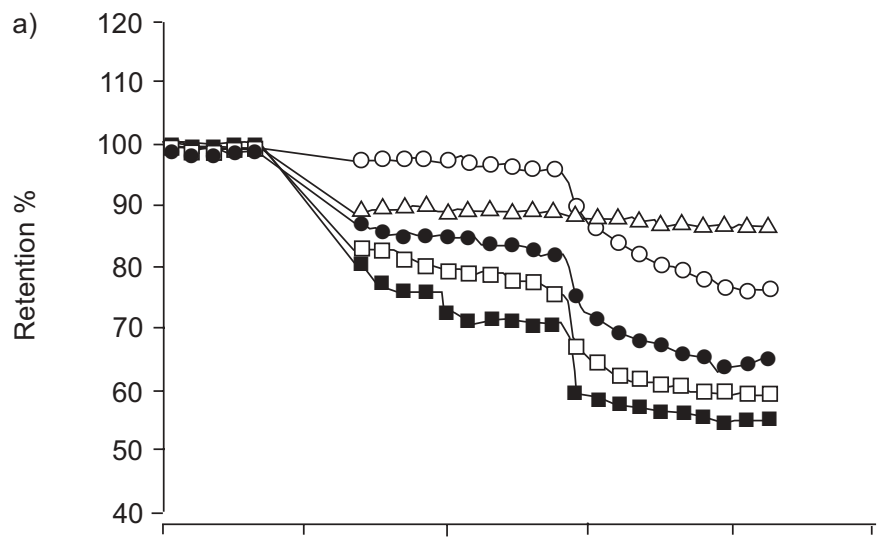

b)
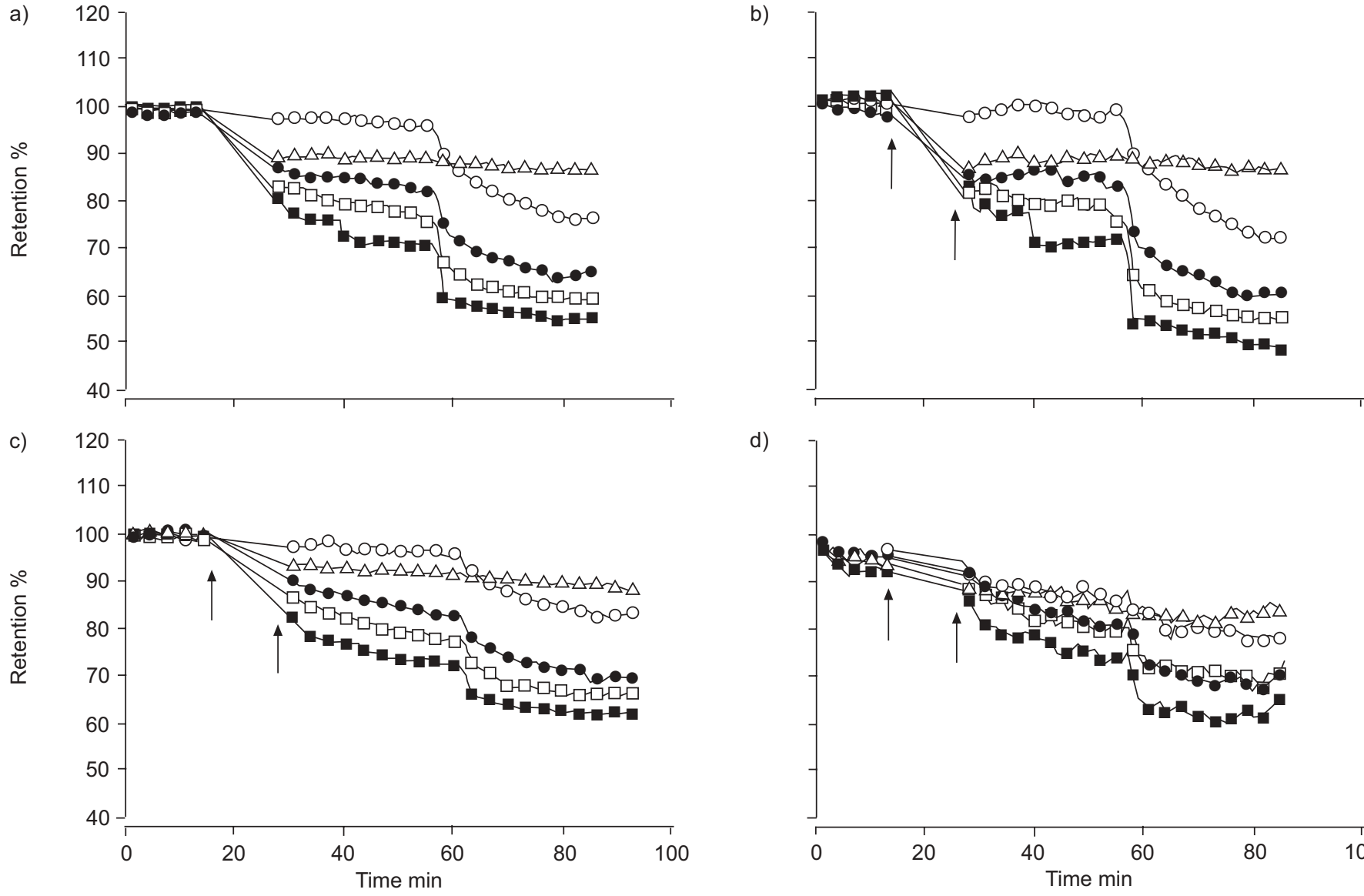

d)

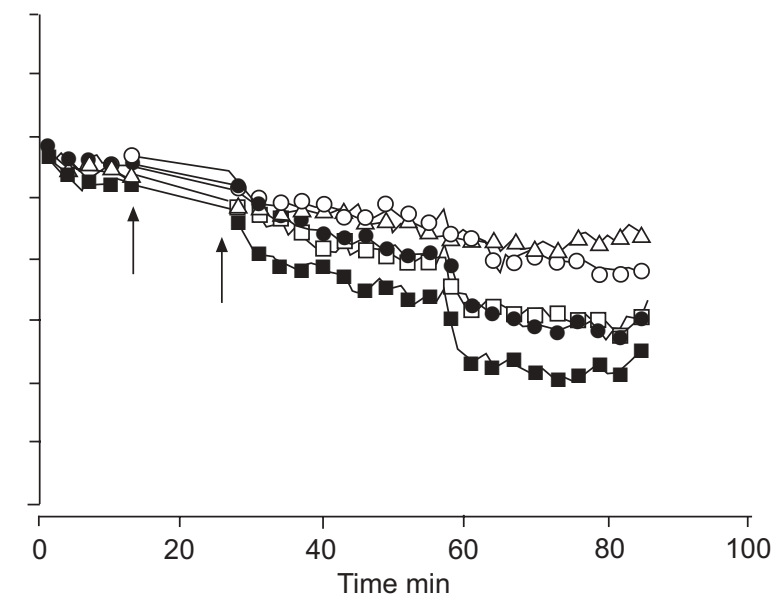

FIGURE 1. Mean percentage retention curves over 90 min of total imaging time in a) the whole right lung, b) right central, c) right intermediate and d) right peripheral regions in 14 subjects with bronchiectasis studied on five visits involving: baseline $(\bigcirc)$; control $(\triangle)$; $160 \mathrm{mg}$ mannitol $(\bullet) ; 320 \mathrm{mg}$ mannitol $(\square)$; and $480 \mathrm{mg}$ mannitol $(\mathbf{\square})$. Arrows represent intervention period. During the last $30 \mathrm{~min}$, subjects were asked to cough 100 times voluntarily. The control visit involved the maximum number of coughs provoked by the mannitol doses during the intervention but did not include coughing during the last $30 \mathrm{~min}$. The results demonstrate an increase in clearance in response to all doses of mannitol compared with baseline and control. Clearance increased in the central and intermediate regions with increasing dose of mannitol but not in the peripheral region.

significant correlation between clearance in the whole right lung and central region and the number of coughs over the intervention period or over the 45-min period from the start of mannitol inhalation $(\mathrm{p}>0.6)$.

\section{Radioaerosol deposition}

The initial radioaerosol distribution in the whole right lung was similar on all study days $(22.2 \pm 2.4,26.1 \pm 2.9,26.3 \pm 3.6$, $25.4 \pm 3.0$ and $25.4 \pm 3.4 \%$ for baseline, control, 160, 320 and

\section{TABLE 2 Clearance at specified intervals in the whole right lung in 14 subjects with bronchiectasis}

\begin{tabular}{|c|c|c|c|c|c|}
\hline Study & \multicolumn{3}{|c|}{ Clearance } & \multicolumn{2}{|c|}{ Total clearance from start intervention } \\
\hline Baseline & $2.0 \pm 0.8$ & $2.4 \pm 0.7$ & $2.8 \pm 1.3$ & $4.7 \pm 1.2$ & $24.1 \pm 6.0$ \\
\hline Control & $2.8 \pm 2.1$ & $9.6 \pm 2.4^{*}$ & $3.0 \pm 1.4$ & $10.6 \pm 2.6$ & $13.1 \pm 3.0^{*}$ \\
\hline \multicolumn{6}{|c|}{ Mannitol dose $\mathrm{mg}$} \\
\hline 320 & $2.0 \pm 1.0$ & $15.3 \pm 4.5^{\star \star *}$ & $8.5 \pm 2.0^{\star . *}$ & $22.8 \pm 4.2^{* * * . \# \# \#}$ & $40.9 \pm 5.6^{\star \star *} . \# \# \#$ \\
\hline 480 & $1.7 \pm 0.8$ & $20.8 \pm 5.4^{\star \star \star}, \# \#$, & $11.9 \pm 3.0^{\star \star}, \# \#$, & $31.0 \pm 4.7^{\star \star \star}, \# \# \#, \cdots,+$ & $46.0 \pm 5.2^{\star \star \star}, \# \# \#, \bullet$ \\
\hline
\end{tabular}

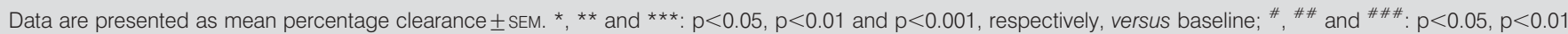
and $p<0.001$, respectively, versus control; " and ${ }^{\top}{ }^{*}: p<0.05$ and $p<0.001$, respectively, versus 160 mg mannitol; ${ }^{+}$: $p<0.05$ versus 320 mg mannitol. 


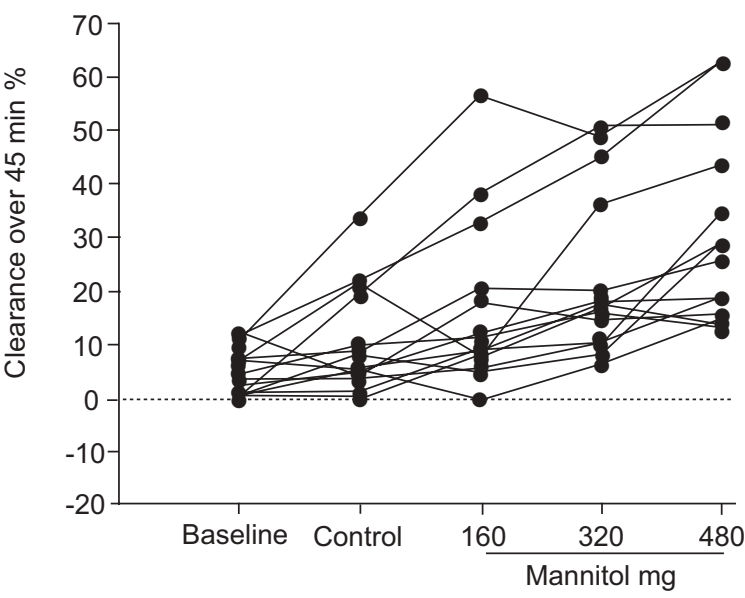

FIGURE 2. Clearance over $45 \mathrm{~min}$, measured since the start of the intervention, in the whole right lung of 14 subjects with bronchiectasis. Clearance increased with increasing doses of mannitol in the majority of subjects. Mean $\pm \mathrm{SE}$ percentage clearance over $45 \mathrm{~min}$ for baseline, control, 160, 320 and $480 \mathrm{mg}$ mannitol were $4.7 \pm 1.2,10.6 \pm 2.6,16.7 \pm 4.2,22.8 \pm 4.2$ and $31.0 \pm 4.7 \%$, respectively.

$480 \mathrm{mg}$ mannitol, respectively; $\mathrm{p}>0.2$ ). The radioaerosol deposition was consistent with the FEV1 \% predicted being similar on all study days $(76.7 \pm 3.6,76.5 \pm 3.7,77.0 \pm 3.7$,
$76.0 \pm 3.4$ and $76.6 \pm 3.7 \%$ for baseline, control, 160,320 and $480 \mathrm{mg}$ mannitol, respectively; $\mathrm{p}>0.4$ ).

\section{DISCUSSION}

The present study investigated the acute effect of clearance of mucus in response to three doses of mannitol. The key finding herein is that clearance of mucus increases with increasing doses of mannitol and that clearance can be further enhanced by voluntary cough in patients with bronchiectasis.

The majority of subjects had extensive bronchiectasis and poor baseline clearance $(<10 \%$ over $60 \mathrm{~min})$, consistent with previous findings [1-5]. However, the majority of subjects had improved clearance, which was dose dependent after mannitol. Clearance over $45 \mathrm{~min}$ from the start of intervention increased to 16.7, 22.8 and $31 \%$ with mannitol doses 160, 320 and $480 \mathrm{mg}$, respectively. These findings are in agreement with previous findings of increasing concentrations of hypertonic saline (3, 7 and $12 \%)$ in cystic fibrosis, although the increases in clearance achieved with 7 and $12 \%$ hypertonic saline compared with control were very similar [20].

Mannitol increased clearance in all regions of the lung, consistent with previous clearance studies [5] and with deposition studies [21, 22], showing that mannitol is deposited in the lung in a diffuse distribution pattern. The magnitude of

TABLE 3 Clearance at specified intervals in the right central, intermediate and peripheral regions of the lung in 14 subjects with bronchiectasis

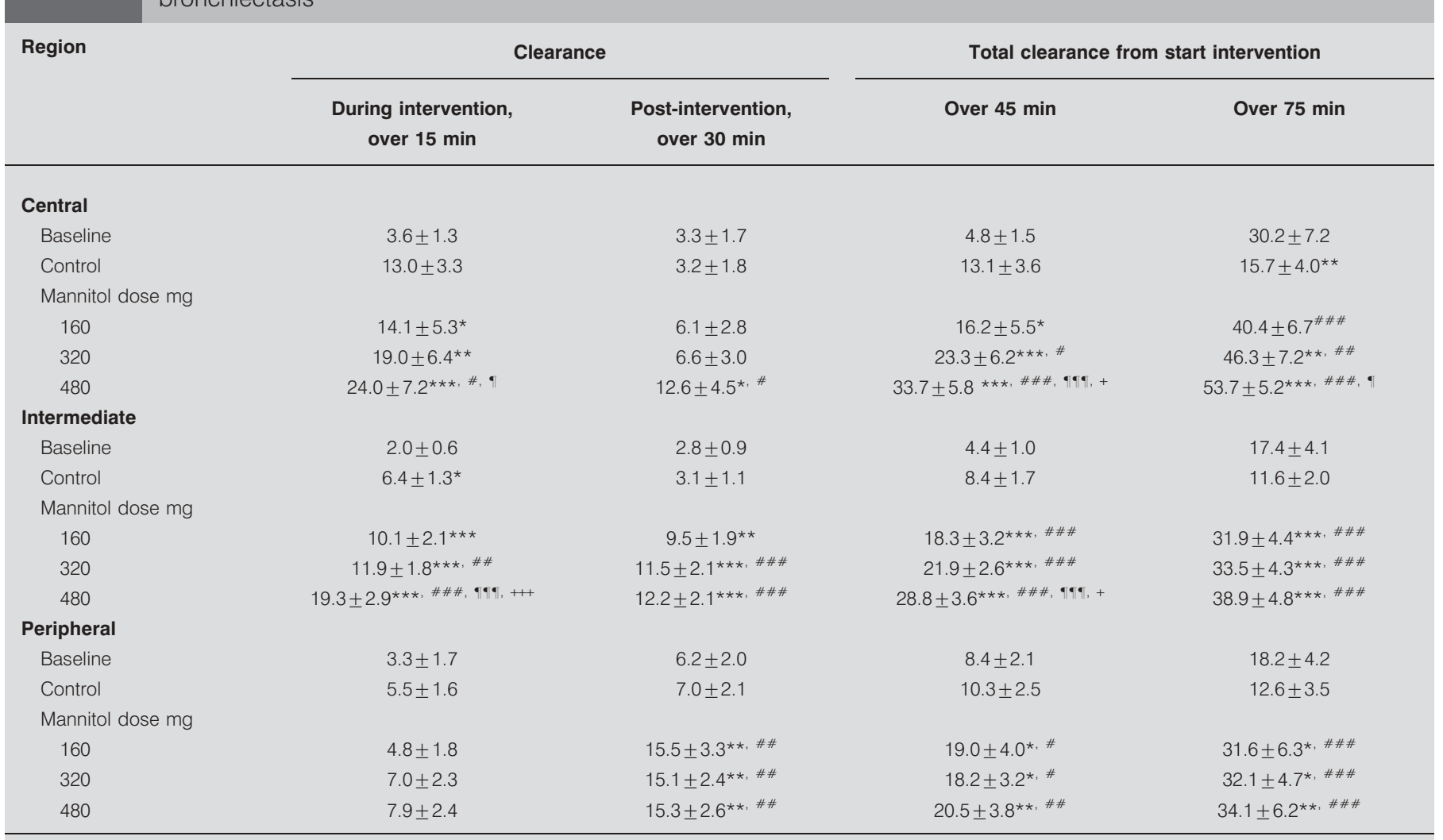

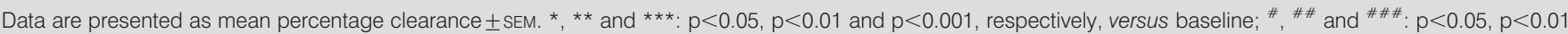
and $p<0.001$, respectively, versus control; " and ${ }^{\cdots}$ : $p<0.05$ and $p<0.001$, respectively, versus 160 mg mannitol; ${ }^{+}$and ${ }^{+++}$: $p<0.05$ and $p<0.001$, respectively, versus $320 \mathrm{mg}$ mannitol. 


\begin{tabular}{|c|c|c|c|}
\hline TABLE 4 & \multicolumn{3}{|c|}{$\begin{array}{l}\text { Total increase in clearance }{ }^{\#} \text { over } 45 \text { min with } \\
\text { each dose of mannitol in the whole right lung and } \\
\text { defined regions in } 14 \text { subjects with } \\
\text { bronchiectasis }\end{array}$} \\
\hline \multirow{2}{*}{$\begin{array}{l}\text { Lung } \\
\text { region }\end{array}$} & \multicolumn{3}{|c|}{ Mannitol } \\
\hline & $160 \mathrm{mg}$ & $320 \mathrm{mg}$ & $480 \mathrm{mg}$ \\
\hline $\begin{array}{l}\text { Whole right } \\
\text { lung }\end{array}$ & $6.1(0.5-11.7)^{+}$ & $12.2(5.7-18.7)^{\star \star \star}$ & $20.4(12.4-28.4)^{\circ}$ \\
\hline Central & $2.9(-6.2-11.9)$ & $10.2(-0.3-20.7)^{\star \star \star}$ & $20.5(9.7-31.5)^{\star \star \star}$ \\
\hline Intermediate & $9.9(4.6-15.1)^{\star \star *}$ & $13.5(8.0-19.0)^{\bullet}$ & $20.3(13.3-27.4)^{\circ}$ \\
\hline Peripheral & $8.7(1.1-16.3)^{\star}$ & $8.0(2.3-13.7)^{\star}$ & $10.3(1.1-19.4)^{\star \star}$ \\
\hline \multicolumn{4}{|c|}{ 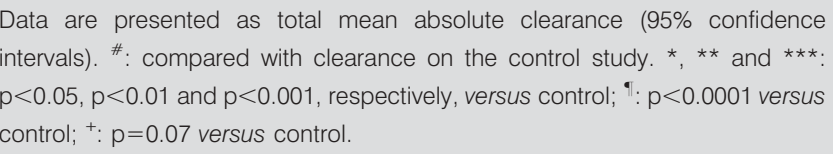 } \\
\hline
\end{tabular}

the increase in clearance in these bronchiectasis subjects was dose dependent in the central and intermediate regions, but not in the peripheral region. Clearance over $45 \mathrm{~min}$ with $480 \mathrm{mg}$ of mannitol was 34, 29 and $20 \%$ in the central, intermediate and peripheral regions, respectively, compared with $\sim 5-8 \%$ at baseline.

It is evident that the highest dose of mannitol used in the present study $(480 \mathrm{mg}$ ) increased clearance of mucus the most in the majority of subjects compared with other doses of mannitol (160 and $320 \mathrm{mg}$ ). The $95 \%$ CIs showed an overlap in the increase in clearance between the doses used. However, the increase in clearance with each dose above the control, suggests that the effect was quite distinct between doses of 160 and $480 \mathrm{mg}$ mannitol. Apparently, a dose difference of $160 \mathrm{mg}$ was too small to achieve a sufficiently distinct increase in clearance to avoid overlap in the $95 \%$ CIs.

The clearance over $45 \mathrm{~min}$ with $480 \mathrm{mg}$ is very similar to the clearance found with $400 \mathrm{mg}$ in different groups of bronchiectasis patients [4, 5]. More importantly, clearance with $480 \mathrm{mg}$ was $\sim 30 \%$ over $45 \mathrm{~min}$, a baseline clearance rate found in young, healthy subjects [23, 24]. Short-term clinical trials $[13,14]$ in patients with bronchiectasis using $400 \mathrm{mg}$ of mannitol administered twice daily provide evidence that this dose is sufficient to improve the health-related quality of life. Patients with a range in severity of bronchiectasis were included in those studies [13, 14], but were not classified accordingly. As the present study finds that mucus clearance is dose dependent, the clinical effect of mannitol with doses $<400 \mathrm{mg}$ needs to be investigated in patients with differences in the severity of bronchiectasis.

The increase in clearance of mucus in response to mannitol is probably due to many factors. Mucus in patients with bronchiectasis has a higher than usual percentage of solid content, reflecting dehydration [13]. Dehydration of mucus can occur as a result of imbalance between the load of mucus secreted and the water available at the airway surface [25]. Dehydrated mucus is viscous, sticky and difficult to clear. As mannitol is an osmotic agent, it creates the driving force for
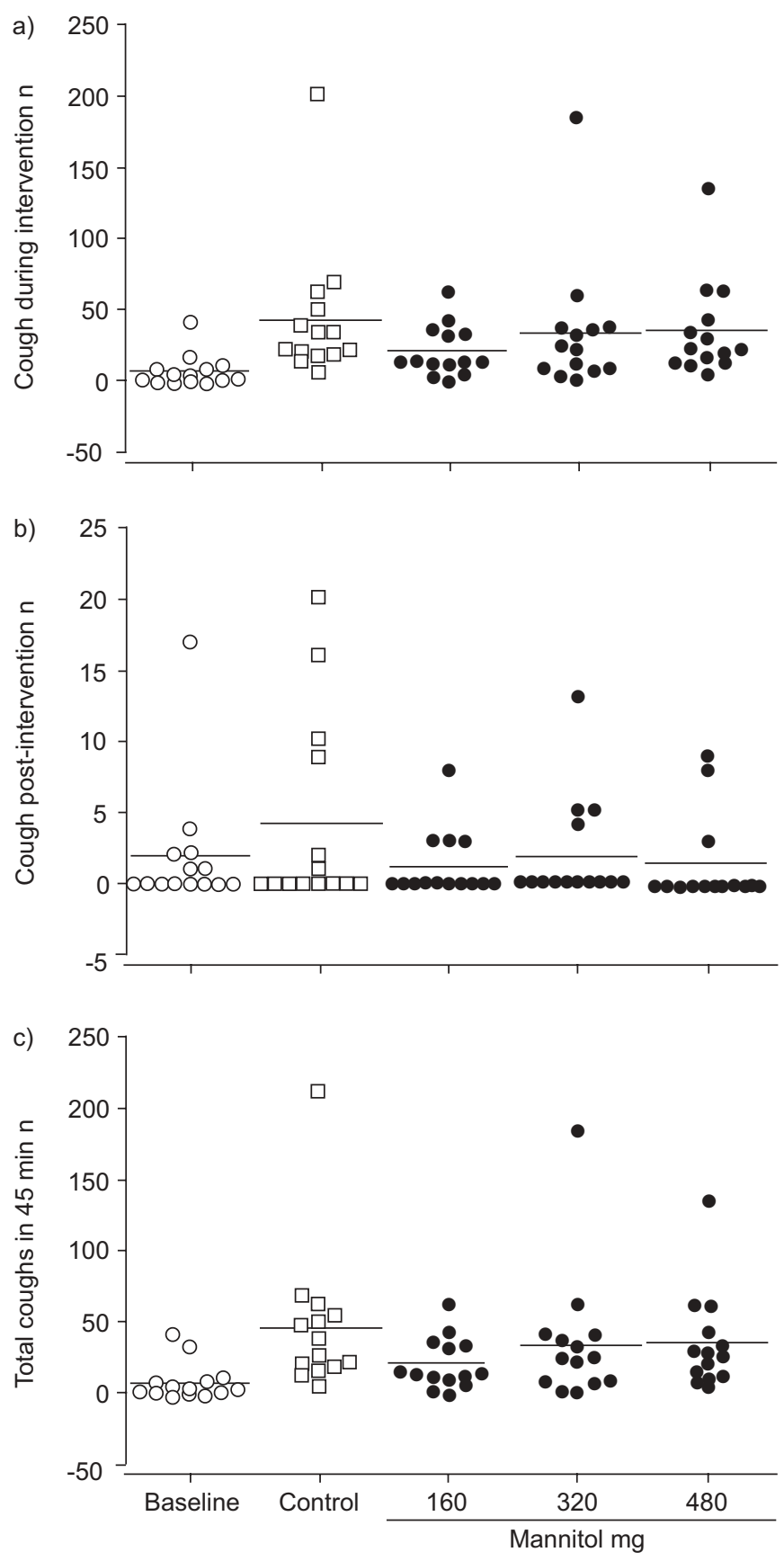

FIGURE 3. Number of coughs a) during intervention, b) post-intervention and c) in total over 45 min from the start of the intervention on the five visits. The control involved the maximum number of coughs provoked by the mannitol doses during the intervention. The horizontal bars are mean values. The median values are: a) 3, 27, 14, 23 and 22 for baseline, control, 160, 320 and 480 mg mannitol, respectively; b) 0 for all conditions; and c) 4, 33, 15, 24 and 28 for baseline, control, 160, 320 and $480 \mathrm{mg}$ mannitol, respectively.

water efflux into the airway lumen. There is evidence that mannitol reduces the proportion of solid content and improves the surface properties of sputum $[13,26]$.

The increase in clearance with increasing doses of mannitol may relate to the greater efflux of water into the airway lumen in response to the higher osmotic force. While the increase in 
the osmolarity of the airway fluid after mannitol deposition is likely to be transient due to re-establishment of the osmotic equilibrium, the increase in volume of water in the airway lumen should be sustained for as long as the mannitol is present. Mannitol is not absorbed and it has low permeability; therefore, unless it is expectorated with the sputum, it should remain in the lumen, sustaining its effect, for some hours [27].

Inhalation of mannitol provoked cough both during and after the administration; however, the increase in clearance that occurred during the intervention with mannitol is unlikely to be accounted for by the cough it provoked. This is because the cough number was greater during the intervention on the control day and yet the clearance was significantly less compared with any of the mannitol doses, assuming that the intensity and effectiveness of voluntary cough is the same as that of spontaneous cough. Also, evidence that the dose effect is not cough related is provided by the fact that the clearance was dose related but the cough frequency during intervention was not (i.e. a similar cough frequency was recorded, irrespective of the mannitol dose). In addition, there was no correlation between the number of coughs provoked by mannitol and clearance of mucus, an observation consistent with previous findings $[4,5]$.

Mannitol has a pleasant taste and the cough provoked by mannitol is well tolerated. Most patients with bronchiectasis undergo physiotherapy treatment. Physiotherapy also provokes cough, aiming to help expectoration of excessive secretions. Therefore, mannitol could also be used as a help to physiotherapy treatment in patients with bronchiectasis, especially since voluntary coughing, $30 \mathrm{~min}$ after inhalation of mannitol, further enhanced clearance in all regions. Most of these subjects had a well-preserved expiratory airflow, which is required for the cough to be effective in clearing mucus [28]. However, it is obvious from the present study that clearance in the presence of mannitol combined with cough manoeuvres can be twice that of the clearance with cough in the absence of mannitol, an enhancement that is seen even in the peripheral region. In the presence of mannitol, it is likely that both an increase in water in the airway lumen and changes in the sputum properties contribute to a greater increase in overall clearance.

Some patients with bronchiectasis have airway hyperresponsiveness to mannitol. The prevalence of hyperresponsiveness in patients with bronchiectasis taking inhaled corticosteroids is $18.9 \%$, and $27.6 \%$ in those not taking them [29]. In the present study, three subjects who had a decrease in FEV1 $>15 \%$ after inhaling $635 \mathrm{mg}$ of mannitol, following an approved protocol [15], were excluded from the study. It is highly recommended that patients are assessed prior to receiving treatment with inhaled mannitol in order to avoid bronchoconstriction.

In conclusion, the present study confirms the acute increase in the clearance of mucus in response to inhaling mannitol in patients with bronchiectasis. These findings have been extended to show that the acute beneficial effect of mannitol on the clearance of mucus is increased when the dose is increased. The results of the present and previous studies support doses $>400 \mathrm{mg}$ of mannitol for achieving clearance of mucus three-fold from baseline clearance and for achieving long-term clinical outcomes in patients with bronchiectasis. It is arguable whether the results of the present study support clinical use of lower doses of mannitol in mild to moderate disease. However, a lower dose, such as $320 \mathrm{mg}$, may prove to be clinically effective in patients with mild to moderate disease. It is likely that the dose of mannitol needed for effective clearance of mucus may differ among patients according to the severity of the disease.

In addition, clearance can be further improved if administration of mannitol is followed, shortly after, by some cough manoeuvres. The present data provide guidance concerning the dose of mannitol for treatment in patients with bronchiectasis and for clinical trials with a larger number of subjects to show the long-term clinical effect with each dose of mannitol.

\section{ACKNOWLEDGEMENTS}

The present authors would like to thank the technical staff of the Dept of Positron Emission Tomography and Nuclear Medicine of the Royal Prince Alfred Hospital, Camperdown, Australia, for their help, the patients for taking part in the study and the physicians for referring their patients.

\section{REFERENCES}

1 Lourenço RV, Loddenkemper R, Carton RW. Patterns of distribution and clearance of aerosols in patients with bronchiectasis. Am Rev Respir Dis 1972; 106: 857-866.

2 Currie DC, Pavia D, Agnew JE, et al. Impaired tracheobronchial clearance in bronchiectasis. Thorax 1987; 42: 126-130.

3 Isawa T, Teshima T, Hirano T, et al. Mucociliary clearance and transport in bronchiectasis: global and regional assessment. J Nucl Med 1990; 31: 543-548.

4 Daviskas E, Anderson SD, Eberl S, Chan HK, Bautovich G. Inhalation of dry powder mannitol improves clearance of mucus in patients with bronchiectasis. Am J Respir Crit Care Med 1999; 159: 1843-1848.

5 Daviskas E, Anderson SD, Eberl S, Chan HK, Young IH. The 24-h effect of mannitol on the clearance of mucus in patients with bronchiectasis. Chest 2001; 119: 414-421.

6 Wilson CB, Jones PW, O'Leary CJ, Cole PJ, Wilson R. Validation of the St. George's Respiratory Questionnaire in bronchiectasis. Am J Respir Crit Care Med 1997; 156: 536-541.

7 Martínez-García MA, Perpiñá-Tordera M, Román-Sánchez P, Soler-Cataluña JJ. Quality-of-life determinants in patients with clinically stable bronchiectasis. Chest 2005; 128: 739-745.

8 Rogers DF, Barnes PJ. Treatment of airway mucus hypersecretion. Ann Med 2006; 38: 116-125.

9 Rubin BK. The pharmacologic approach to airway clearance: mucoactive agents. Respir Care 2002; 47: 818-822.

10 Pryor JA. Physiotherapy for airway clearance in adults. Eur Respir J 1999; 14: 1418-1424.

11 McIlwaine M. Physiotherapy and airway clearance techniques and devices. Paediatr Respir Rev 2006; 7: Suppl. 1, S220-S222.

12 van der Schans CP, Postma DS, Koëter GH, Rubin BK. Physiotherapy and bronchial mucus transport. Eur Respir J 1999; 13: 1477-1486.

13 Daviskas E, Anderson SD, Gomes K, et al. Inhaled mannitol for the treatment of mucociliary dysfunction in patients 
with bronchiectasis: effect on lung function, health status and sputum. Respirology 2005; 10: 46-56.

14 Daviskas E, Turton JA, Anderson SD, Young IH, Lassig A, Charlton B. A placebo controlled trial with inhaled mannitol improves health related quality of life in patients with bronchiectasis. Eur Resp J 2004; 24: Suppl. 48, 707s.

15 Brannan JD, Anderson SD, Perry CP, et al. The safety and efficacy of inhaled dry powder mannitol as a bronchial provocation test for airway hyperresponsiveness: a phase 3 comparison study with hypertonic $(4.5 \%)$ saline. Respir Res 2005; 6: 144 .

16 Quanjer PH, Tammeling GJ, Cotes JE, Pedersen OF, Peslin R, Yernault JC. Lung volumes and forced ventilatory flows. Report Working Party Standardization of Lung Function Tests, European Community for Steel and Coal. Official Statement of the European Respiratory Society. Eur Respir J 1993; Suppl. 16, 5-40.

17 Phipps PR, Gonda I, Anderson SD. Apparatus for the control of breathing patterns during aerosol inhalation. J Aerosol Med 1992; 5: 155-170.

18 Bailey DL, Fulton RR, Jackson CB, Hutton BF, Morris JG. Dynamic geometric mean studies using a single headed rotating gamma camera. J Nucl Med 1989; 30: 1865-1869.

19 Phipps PR, Gonda I, Bailey DL, Borham P, Bautovich G, Anderson SD. Comparisons of planar and tomographic gamma scintigraphy to measure the penetration index of inhaled aerosols. Am Rev Respir Dis 1989; 139: 1516-1523.

20 Robinson M, Hemming AL, Regnis JA, et al. Effect of increasing doses of hypertonic saline on mucociliary clearance in patients with cystic fibrosis. Thorax 1997; 52: 900-903.

21 Glover W, Chan HK, Eberl S, Daviskas E, Anderson S. Lung deposition of mannitol powder aerosol in healthy subjects. J Aerosol Med 2006; 19: 522-532.

22 Glover W, Chan HK, Eberl S, Daviskas E, Verschuer J. Effect of particle size of dry powder mannitol on lung deposition in healthy volunteers. Int J Pharm 2008; 349: 314-322.

23 Daviskas E, Anderson SD, Gonda I, et al. Inhalation of hypertonic saline aerosol enhances mucociliary clearance in asthmatic and healthy subjects. Eur Respir J 1996; 9: 725-732.

24 Robinson M, Eberl S, Tomlinson C, et al. Regional mucociliary clearance in patients with cystic fibrosis. J Aerosol Med 2000; 13: 73-86.

25 Boucher RC. Relationship of airway epithelial ion transport to chronic bronchitis. Proc Am Thorac Soc 2004; 1: 66-70.

26 Daviskas E, Anderson SD, Young IH. Inhaled mannitol changes the sputum properties in asthmatics with mucus hypersecretion. Respirology 2007; 12: 683-691.

27 Tarran R, Grubb BR, Parsons D, et al. The CF salt controversy: in vivo observations and therapeutic approaches. Mol Cell 2001; 8: 149-158.

28 Foster WM. Mucociliary transport and cough in humans. Pulm Pharmacol Ther 2002; 15: 277-282.

29 Anderson SD, Daviskas E, Turton J, Perry C, Young IH. Prevalence of bronchoconstriction in patients with bronchiectasis assessed prior to treatment with a dry powder preparation of mannitol. Eur Resp J 2007; 30: Suppl. 51, $306 \mathrm{~s}$. 